\title{
Dielectric Breakdown Strength of Polymer Nanocomposites-The Effect of Nanofiller Content
}

\author{
M. Takala \\ ABB Oy, Motors and Generators, Tampere, Finland
}

\begin{abstract}
Insulation materials can be tailored by compounding nanofillers and polymer materials. The advantageous changes in properties of polymer nanocomposites can be explained by the large interface area of the nanofillers. Theoretical models developed in the field of nanodielectrics concentrate on the analysis of the interface volume.

Dielectric breakdown strength (DBS) is one of the most important properties of an insulation material. The DBS of nanocomposites depends heavily on the nanofiller content and even small quantities can cause improvement. This is linked to the maximum interface volume achieved already at low nanofiller concentrations. Homogeneous nanodispersion is the key for DBS increase and reliable results. Often the most profitable nanofiller quantities are below $5 \mathrm{wt}-\%$. The same kind of behaviour can be seen with different voltage shapes, but with dc voltage the increase is bigger. DBS has a maximum value with respect to nanofiller amount and decreases thereafter. Filler quantities around $5 \mathrm{wt}-\%$ and even lower are the most attractive considering DBS of nanocomposites.
\end{abstract}

\section{Introduction}

Nanofillers or nanoadditives are defined as material having one dimension less than $100 \mathrm{~nm}$. In the field of insulation the word "nanofiller" is mostly used. Polymer nanocomposites are defined as polymers with a small amount $(0.1$ to $10 \mathrm{wt}-\%)$ of nanofillers. Fillers should be homogeneously dispersed in the polymer matrix to form a nanodielectric material $[1,2]$. The mostly used polymers in nanodielectrics research are polyamide (PA), polyethylene (PE), polypropylene (PP), ethylene vinyl acetate (EVA), epoxy resins (EP) and silicone rubbers (SR). Polymers are combined with inorganic nanofillers such as layered silicate (LS), silica $\left(\mathrm{SiO}_{2}\right)$, titania $\left(\mathrm{TiO}_{2}\right)$, alumina $\left(\mathrm{Al}_{2} \mathrm{O}_{3}\right)$ and magnesia $(\mathrm{MgO})$.

The short history of nanodielectrics dates back to 1994 . The first paper using nanodielectrics was published by John Lewis in the Transactions on Dielectrics and Electrical Insulation (Institute of Electrical and Electronics Engineers, IEEE). The paper is entitled "Nanometric Dielectrics" and discusses the future of insulation materials [3]. After a fairly slow start in the 1990's nanodielectrics research has increased rapidly in this millennium, which can be seen in the increasing number of publications and group activities in the International Council on Large Electric Systems (CIGRE) and IEEE. The history and development of nanodielectrics have been described more closely in [1, 2, 4-12].

Polymer nanocomposites are the second generation of filled dielectrics in insulation engineering. The first generation of filled dielectrics is microcomposites, which consist of polymers filled with a large amount (of the order of $50-60 \mathrm{wt}-\%$ ) of micron-sized inorganic fillers (from $100 \mathrm{~nm}$ to $100 \mu \mathrm{m}$ ). If the filler weigth content of nano- and microfillers is the same in the matrix, the interfacial surface (area/volume) between the inorganic fillers and the polymer matrix is larger (typically three orders of magnitude) in nanocomposites than in microcomposites [13]. The weight content of the nanoparticles is usually quite low (less than $10 \mathrm{wt}-\%$ ) because of the low percolation threshold. When nanoparticle content increases beyond the percolation threshold, the nanocomposite may lose its beneficial dielectric properties [4]. The small filler amounts in nanocomposites ensure that inherent polymer properties, e.g. density, remain almost unchanged. The size difference in nano- and microfillers leads to nine orders of magnitude difference in the number of particles at the same filler weight content if the densities and volume contents of fillers are the same. Therefore the distances between neighbouring fillers are much smaller (nanometers) in nanocomposites than in conventional microfilled polymers, if fillers are homogeneously dispersed. More comprehensive discussions on nanoand microcomposites have been published in [13-18].

\section{Affecting factors on dielectric breakdown strength}

DBS is one of the most important properties of an insulation material. As discussed earlier, the properties of polymer nanocomposites are mainly explained by a large interfacial area of nanofillers. This interfacial area is responsible for the interaction of the electrical field between the matrix polymer and nanofiller [10, 19-21]. The DBS of the nanocomposites depends heavily on the nanofiller content and even small quantities can cause improvement. Often the most profitable nanofiller quantities are below $5 \mathrm{wt}-\%$, as has been noted in [2226]. The ac DBS of 3 wt- $\%$ octamethyl POSS-PP composite increased $22 \%$ compared to the reference PP. The LI DBS of 1 wt- $\%$ octaglycidyldimethylsilyl 
POSS-EP nanocomposite increased $26 \%$ compared to the reference EP. These changes are linked to the ability of POSS particles to trap charges [22] and to the maximum interfacial area achieved already at low nanofiller concentrations [27]. Good homogeneous nanodispersion is the key to DBS increase and reliable results [28]. The risk of agglomerates increases with nanofiller content. Agglomerates decrease the DBS as in microcomposites.

The DBS behaviour of nanocomposites may be reflected in changes in the space charge distribution, reduction in the internal electric field caused by the nanofiller size and changes in the polymer morphology [28]. Nelson also emphasizes the effects of the scattering of electrons in high field regions, electron trapping and free volume within the polymer structure $[10,20]$. When the layers of nanoparticles are connected, paths of high conductivity may form. These local short circuit paths lead to faster recombination of space charges in nanocomposites. These effects result in lower space charge accumulation and lower local internal fields due to space charges in nanocomposites. Scattering of electrons decreases the kinetic energy preventing ionization and the deep traps reduce the mobility of charge carriers [29].

Vaughan et al. suggest that the addition of nanofillers changes the crystal growth mode in MMT-PE nanocomposite [21]. The crystals can be smaller if the growth centres (e.g. nanoparticles) are close to each other. However, the crystallinity degree has been observed to increase with mica-PA nanocomposite [30]. Roy et al. conclude that crystallinity is not as such a significant factor in controlling DBS, the nanoparticles in the crystalline phase may disrupt the path provided to the charge carriers and lead to an increase in DBS [28]. In [31] it is also suggested that the increase of ac DBS in $\mathrm{CaCO}_{3}$-PP composites may be due to the high melting point of $\mathrm{CaCO}_{3}\left(1340{ }^{\circ} \mathrm{C}\right)$ and strengthening of weak areas between spherulites. Murakami et al. also suggest that in MgO-LDPE nanocomposite the increase in dc DBS is related to thermal processes [32].

The general idea in DBS measurements is to compare the matrix polymer with nanofillers to the reference polymer matrix. Stabilizers are also commonly used e.g. against ultra violet radiation ageing. The effect of stabilizers on the DBS of reference polymer can be defined by measuring reference material with and without stabilizers, although this may be difficult in practice. It is important to maintain stable measurement conditions during the DBS measurements. Air pressure, humidity and temperature all affect the measured properties and materials. The temperature effect of nanocomposite DBS has been studied in [28]. Roy et al. conducted dc DBS measurements at four different temperatures $25^{\circ} \mathrm{C}, 60{ }^{\circ} \mathrm{C}, 70{ }^{\circ} \mathrm{C}$ and $80{ }^{\circ} \mathrm{C}$ and for four different $\mathrm{SiO}_{2}$ surface treatments. DBS decreased as a function of temperature with all compositions and with the reference material. The DBS behaviour of nanocomposites is affected by environmental condition but the actual effect in each case also depends on the voltage shape used (ac, dc, LI) and the matrix polymer and nanofiller. Thus, the importance of each factor varies case by case. Figure 1 presents the variables and factors affecting the DBS of nanocomposites. DBS depends on many variables and factors which also depend on each other. They all need to be considered when conducting DBS measurements and analysing the results.

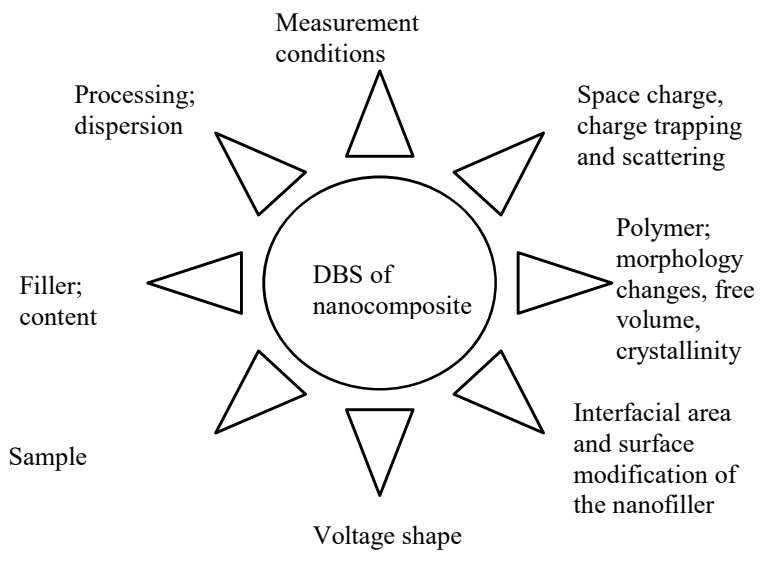

Fig. 1 - Variables and factors affecting the DBS of nanocomposites.

\section{Effect of the voltage shape}

As indicated in Chapter 2, there are mechanisms related to nanocomposites which increase the short-term breakdown voltage. These mechanisms are dependent on the voltage shape used in the DBS measurements. The ac and LI DBS of nanocomposites are usually harder to increase than the dc DBS, as has been noted in [22-26]. The mean values of ac and dc DBS of $5 \mathrm{wt}-\%$ $\mathrm{SiO}_{2}$-PP nanocomposite increased $20 \%$ and $52 \%$ respectively compared to the reference PP.

As Danikas et al. [4] concluded, reduction of space charge accumulation improves dc voltage performance and scattering mechanism is the reason for improved ac and LI voltage performance. This has also been supported by $\mathrm{Hu}$ et al. [29]. Roy et al. emphasize that the increased dc DBS is a common property for all nanocomposites [28]. Smith et al. also report that dc DBS measurements provided higher breakdown strength values with $\mathrm{SiO}_{2}$-XLPE nanocomposites than the peak values of the ac DBS measurements and the surface modification of $\mathrm{SiO}_{2}$ nanoparticles had a positive effect [33]. The accumulation of shielding space charge is a process which needs time to develop. Thus, in ac or in fast impulse voltage DBS measurement $(1.2 / 50 \mu \mathrm{s})$, the effect of shielding space charge disappears. The large interfacial area creates opportunities for a scattering mechanism. During ac and LI conditions, this may 
become the primary mechanism for the increase in the DBS of nanocomposites.

Usually the DBS values of the nanocomposites fit into the Weibull distribution. A common conclusion for the DBS results with ac and dc voltage shapes is that breakdown probability at $62.3 \%(\alpha)$ increases or remains at the reference level, but scattering of the data decreases $(\beta$ increases) $[19,22-26,29,34,35]$. Nanocomposites have smaller scattering for DBS values. The breakdown phenomenon in homogeneous nanocomposites is more stable than in the reference matrix polymer. The phenomenon has a positive impact on insulation system design, where safety margins may be reduced. It is actually as important as increase of $\alpha$. Hoyos et al. concluded that $\mathrm{SiO}_{2}$-LDPE and LS-LDPE nanocomposites are defect-free as regards electrically weak spots [36]. This improvement in $\beta$ values is a good sign of proper nanodispersion in nanocomposites.

Figure 2 presents third order polynomial fittings for the DBS results of nanocompostites as a function of nanofiller content. It shows that the same kind of behaviour with different voltage shapes can be achieved with nanocomposites, but with dc voltage the increase is bigger. The difference between the dc vs. ac DBS values is in the order of $\sqrt{2}$, because ac DBS is given as root mean square (RMS) value. The peaks of the fittings are approximately in the same position with respect to nanofiller content. DBS has a maximum value with respect to nanofiller amount and decreases thereafter. Filler quantities around $5 \mathrm{wt}-\%$ and even lower are the most attractive considering DBS of nanocomposites. This kind of behaviour is similar to the interphase volume model presented by Raetzke [27].

\section{Conclusion}

Dielectric breakdown strength (DBS) is one of the most important properties of an insulation material. The DBS of nanocomposites depends heavily on the nanofiller content and even small quantities can cause improvement. This is linked to the maximum interface volume achieved already at low nanofiller concentrations. Homogeneous nanodispersion is the key for DBS increase and reliable results. Often the most profitable nanofiller quantities are below $5 \mathrm{wt}-\%$. The same kind of behaviour can be seen with different voltage shapes, but with dc voltage the increase is bigger. DBS has a maximum value with respect to nanofiller amount and decreases thereafter. Filler quantities around $5 \mathrm{wt}-\%$ and even lower are the most attractive considering DBS of nanocomposites.

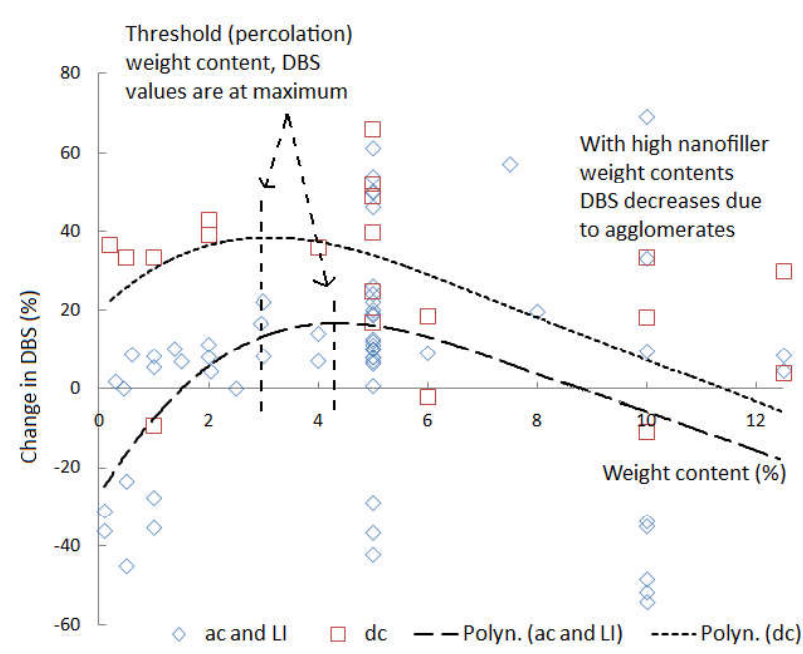

Fig. 2 - DBS of the nanocomposites as a function of filler content. Diamonds are the measurement results for ac and LI voltages and squares for dc voltage. Third order polynomial fittings are presented with broken lines [37].

\section{References}

[1] T. Tanaka, "Dielectric Nanocomposites with Insulating Properties", IEEE Trans. Dielectr. Electr. Insul., Vol. 12, pp. 914-928, 2005.

[2] T. Tanaka and M. Frechette, "Emerging Nanocomposite Dielectrics", CIGRE Task Force Report D1.16.03, ELECTRA, No. 226, pp. 24-32, 2006.

[3] T. J. Lewis, "Nanometric Dielectrics", IEEE Trans. Dielectr. Electr. Insul., Vol. 1, pp. 812-825, 1994.

[4] M. G. Danikas and T. Tanaka, "Nanocomposites-A Review of Electrical Treeing and Breakdown", IEEE Electr. Insul. Mag., Vol. 25, pp. 19-25, 2009.

[5] L. A. Dissado and J. C. Fothergill, "Editorial: Dielectrics and Nanotechnology", IEEE Trans. Dielectr. Electr. Insul., Vol. 11, pp. 737-738, 2004.

[6] M. F. Fréchette, M. Trudeau, H. D. Alamdari and S. Boily, "Introductory Remarks on Nanodielectrics", IEEE Conf. Electr. Insul. Dielectr. Phenomena (CEIDP), pp. 92-99, 2001.

[7] M. F. Fréchette and C. W. Reed, "On molecular dielectrics in their role in shaping and controlling nanodielectrics", IEEE Conf. Electr. Insul. Dielectr. Phenomena (CEIDP), pp. 333-337, 2006.

[8] M. F. Fréchette, "Innovation in Dielectric Materials: from Macro to Nanoscales", IEEE Electr. Insul. Conf. (EIC), pp. 514-523, 2009.

[9] J. K. Nelson, J. C. Fothergill, L. A. Dissado and W. Peasgood, "Towards an Understanding of Nanometric Dielectrics", IEEE Conf. Electr. Insul. Dielectr. Phenomena (CEIDP), pp. 295-298, 2002.

[10] J. K. Nelson, "The Promise of Dielectric Nanocomposites", IEEE Intern. Sympos. Electr. Insul. (ISEI), pp. 452-457, 2006.

[11] J. K. Nelson, "Overview of Nanodielectrics: Insulating Materials of the Future", Electrical Insulation Conference and Electrical Manufacturing Expo, pp. 229-235, 2007. 
[12] S. Phillips, T. Haddad and S. Tomczak, "Developments in nanoscience: polyhedral oligomeric silsesquioxane (POSS)-polymers", Current Opinion in Solid State and Materials Science, Vol. 8, pp. 21-29, 2004.

[13] S. Raetzke and J. Kindersberger, "Erosion Behaviour of Nano Filled Silicone Elastomers", Intern. Symp. High Voltage Eng. (ISH), C-09, 2005.

[14] R. J. Fleming, A. Ammala, P. S. Casey and S. B. Lang, "Conductivity and Space Charge in LDPE Containing Nano- and Micro-sized ZnO Particles", IEEE Trans. Dielectr. Electr. Insul., Vol. 15, pp. 118-126, 2008.

[15] J. C. Fothergill, J. K. Nelson and M. Fu, "Dielectric Properties of Epoxy Nanocomposites containing $\mathrm{TiO} 2, \mathrm{Al} 2 \mathrm{O} 3$ and $\mathrm{ZnO}$ fillers", IEEE Conf. Electr. Insul. Dielectr. Phenomena (CEIDP), pp. 406-409, 2004.

[16] J. K. Nelson and Y. Hu, "Nanocomposite Dielectrics-Properties and Implications", J. Phys. D: Appl. Phys., Vol. 38, pp. 213-222, 2005.

[17] S. Singha and M. J. Thomas, "Dielectric Properties of Epoxy Nanocomposites", IEEE Trans. Dielectr. Electr. Insul., Vol. 15, pp. 12-23, 2008.

[18] T. Tanaka, G. C. Montanari and R. Mulhaupt, "Polymer Nanocomposites as Dielectrics and Electrical Insulation perspectives for Processing Technologies, Material Characterization and Future Applications", IEEE Trans. Dielectr. Electr. Insul., Vol. 11, pp. 763-784, 2004.

[19] F. Guastavino, A. Ratto, E. Torello, M. Hoyos, N. García, H. Reinecke, E. Benito and P. Tiemblo, "AC electrical strength measurements on LDPE nanocomposites", IEEE Conf. Electr. Insul. Dielectr. Phenomena (CEIDP), pp. 329-332, 2006.

[20] J. K. Nelson and J. C. Fothergill, "Internal Charge Behaviour of Nanocomposites", Nanotechnology, Vol. 15, pp. 586-595, 2004.

[21] A. S. Vaughan, C. D. Green, Y. Chang and G. Chen, "Nanocomposites for High Voltage Applications: Effect of Sample Preparation on AC Breakdown Studies", IEEE Conf. Electr. Insul. Dielectr. Phenomena (CEIDP), pp. 732-735, 2005.

[22] M. Takala, M. Karttunen, P. Salovaara, S. Kortet, K. Kannus and T. Kalliohaka, "Dielectric Properties of Nanostructured Polypropylene-Polyhedral Oligomeric Silsesquioxane Compounds", IEEE Trans. Dielectr. Electr. Insul., Vol. 15, No. 1, pp. 40-51, 2008.

[23] M. Takala, M. Karttunen, J. Pelto, P. Salovaara, T. Munter, M. Honkanen, T. Auletta and K. Kannus, "Thermal, Mechanical and Dielectric Properties of Nanostructured Epoxy-Polyhedral Oligomeric Silsesquioxane Composites", IEEE Trans. Dielectr. Electr. Insul., Vol. 15, No. 5, pp. 1224-1235, 2008.

[24] M. Takala, H. Ranta, J. Pelto, S. Virtanen, V. Koivu, M. Pettersson and K. Kannus, "Dielectric Properties of Polypropylene-Silica Nanocomposites", Nordic Insulation Symposium (NORD-IS09), pp. 31-35, 2009.

[25] M. Takala, B. Sonerud, H. Ranta, J. Pelto, S. Ahonen, M. Pettersson and K. Kannus, "Effect of Low Amount of Nanosilica on Dielectric Properties of Polypropylene", IEEE Intern. Conf. Solid Dielectr. (ICSD), pp. 187-191, 2010.
[26] M. Takala, H. Ranta, P. Nevalainen, P. Pakonen, J. Pelto, M. Karttunen, S. Virtanen, V. Koivu, M. Pettersson, B. Sonerud and K. Kannus, "Dielectric Properties and Partial Discharge Endurance of Polypropylene-Silica Nanocomposite", IEEE Trans. Dielectr. Electr. Insul., Vol. 17, No. 4, pp. 12591267, 2010.

[27] S. Raetzke and J. Kindersberger, "Resistance to High Voltage Arcing and the Resistance to Tracking and Erosion for Silicone/SiO2 Nanocomposites", Intern. Symp. High Voltage Eng. (ISH), F-10, 2009.

[28] M. Roy, J. K. Nelson, R. K. MacCrone and L. S. Schadler, "Candidate mechanisms controlling the electrical characteristics of silica/XLPE nanodielectrics", J. Mater. Sci., Vol. 42, pp. 37893799, 2007.

[29] Y. Hu, R. C. Smith, J. K. Nelson and L. S. Schadler, "Some mechanistic understanding of the impulse strength of nanocomposites", IEEE Conf. Electr. Insul. Dielectr. Phenomena (CEIDP), pp. 31-34, 2006.

[30] N. Fuse, Y. Ohki, M. Kozako and T. Tanaka, "Possible Mechanism of Superior Resistance of Polyamide Nanocomposites to Partial Discharges and Plasmas", IEEE Trans. Dielectr. Electr. Insul., Vol. 15, pp. 161-169, 2008.

[31] M. Takala, S. Kortet, P. Salovaara, M. Karttunen, K. Kannus, "AC Breakdown Strength of Polypropylene-Calcium Carbonate Compounds", Nordic Insul. Sympos. (NORD-IS), Copenhagen, Denmark, June 11-13, pp. 123-126, 2007.

[32] Y. Murakami, M. Nemoto, S. Okuzumi, S. Masuda, M. Nagao, N. Hozumi, Y. Sekiguchi and Y. Murata, "DC Conduction and Electrical Breakdown of $\mathrm{MgO} / \mathrm{LDPE}$ Nanocomposite", IEEE Trans. Dielectr. Electr. Insul., Vol. 15, pp. 33-39, 2008.

[33] R. C. Smith, C. Liang, M. Landry, J. K. Nelson and L. S. Schadler, "The Mechanisms Leading to the Useful Electrical Properties of Polymer Nanodielectrics", IEEE Trans. Dielectr. Electr. Insul., Vol. 15, pp. 187-196, 2008.

[34] G. C. Montanari, D. Fabiani, F. Palmieri, D. Kaempfer, R. Thomann and R. Mülhaupt, "Modification of Electrical Properties and Performance of EVA and PP Insulation through Nanostructure by Organophilic Silicates", IEEE Trans. Dielectr. Electr. Insul., Vol. 11, pp. 754-762, 2004.

[35] G. C. Montanari, F. Ciani, L. Testa, F. Guastavino, G. Coletti, R. Mülhaupt, "Electric strength, space charge and surface discharge characterization of nanostructured epoxy-silicate insulating materials", Intern. Symp. Electr. Insul. Mat. (ISEIM), pp. 206209, 2005.

[36] M. Hoyos, N. García, R. Navarro, A. Dardano, A. Ratto, F. Guastavino and P. Tiemblo, "Electrical Strength in Ramp Voltage AC Tests of LDPE and Its Nanocomposites with Silica and Fibrous and Laminar Silicates", J. Pol. Sci.: Part B: Pol. Phys., Vol. 46, pp. 1301-1311, 2008.

[37] M. Takala, "Electrical Insulation Materials towards Nanodielectrics", Tampere University of Technology, Doctoral Dissertation (Publication 928), 2010, $63 \mathrm{p}$. 